\title{
PREDICTING THE RISK OF ENCOUNTERING FINANCIAL DIFFICULTIES BY THE EXAMPLE OF ESTONIAN MUNICIPALITIES
}

\author{
Pirgit Lohk \\ Ministry of Finance, Estonia \\ Paavo Siimann \\ Tallinn University of Technology, Estonia
}

\begin{abstract}
The objective of the study is to determine the financial and non-financial indicators which describe the financial difficulties encountered by Estonian municipalities and to prepare a model to predict the risk of encountering financial difficulties. In order to achieve the objective, the study employs multidimensional statistical analysis methods: discriminant analysis and logit analysis. The predictive model is based on the financial and non-financial indicators of Estonian municipalities for the years 2004-2014 and the risk of encountering financial difficulties is defined as the value of the variable primary operating outcome to depreciation of tangible fixed assets of the population over the years 2011-2014. The classification accuracy of the discriminant model comprising seven independent variables found as a result of the analysis is $88 \%$ and the same indicator for the logit model is $87 \%$. The variable with the highest descriptive capacity in predicting the risk of encountering financial difficulties is the ratio of primary operating outcome to the primary operating revenues. The methods of the study and the predictive model prepared make a significant contribution to the development of this field of study in Estonia and are applicable also to other countries where municipalities operate under similar financial management principles.
\end{abstract}

Keywords: municipality, financial difficulties, discriminant analysis, logit.

JEL code: C53, R58

\section{Introduction}

The economic crisis of the past few years has distinctly highlighted to the need to raise the efficiency of countries' budgetary policies. On the one hand it is necessary to ensure macroeconomic stability and sustainability and on the other hand to develop the state's reputation as trustworthy business partner in the eyes of financial institutions and potential investors. State budgetary policy comprises both the central government as well as municipalities, which leads a globally increasing need to be able to evaluate the financial position of municipalities and the sustainability thereof.

At the same time, the increasing decentralisation of public services increases the municipalities' responsibility in using the tax-payers' resources and playing a greater role in the decision-making processes of the local community. In order to ensure a strong local governance system that can organise the provision of high-quality public services now as well as in the future, it is vital that we be able to evaluate the financial position of municipalities and have evaluation methods and indicators which explain how municipalities encounter financial difficulties. Furthermore, this will more easily allow both the central government and the local community to evaluate the sustainability of the municipality while increasing the transparency of using public funds.

The aim of the study is to determine the financial and non-financial indicators that describe the financial difficulties encountered by Estonian municipalities and to prepare a model to predict the risk of encountering financial difficulties. The study uses the financial and nonfinancial data of the total population of Estonian municipalities for the years 2004-2014 
which is available from the databases of the Ministry of Finance and the Population Register. The predictive model is prepared using discriminant analysis and logit analysis, which were chosen based on their suitability to address the issue under study and their use in previous studies. One of the advantages of the study is access to data concerning the total population which the authors of prior studies have lacked and which has been given as one of the reasons why there have been few studies in this field.

The article consists of four parts. The first part provides an overview of prior studies of the financial difficulties of municipalities. The second part provides an overview of the methods and data used in the study. The third part presents the results of the discriminant analysis as well as those of the logit analysis. The final part will provide an overview of the material conclusions reached as a result of the analysis.

\section{Overview of the previous studies}

While private sector financial indicators have been studied extensively over the past decades (e.g. Ohlson 1980, Altman 2000, Becchetti and Sierra 2003, Pompe and Bilderbeek 2005 etc.), the public sector has failed to draw such a great attention from researchers. Consequently, the academic literature in the field is primarily directed towards the private sector both in terms of theoretical and empirical approaches. This has been explained by the fact that traditional financial ratios are unsuitable for evaluating the sustainability of public sector financial position as well as the fact that public services are not offered for profit, making it more difficult to measure performance. Nevertheless, the need to be able to evaluate the financial position of the public sector exists and, thus, the authors, considering the characteristics of the public sector, have, in addition to financial indicators, also included nonfinancial indicators in the study in order to allow relevant conclusions to be drawn on the basis thereof.

Kloha et al developed a 10-point scale for measuring the fiscal stress of municipalities in order to distinguish municipalities experiencing fiscal stress from those that are not. The model comprises nine financial and non-financial indicators, consisting of three financial ratios, three population or revenue growth indicators and three indicators describing the difference in budget revenues and expenditures. (Kloha et al, 2005, pp. 314, 319) Applying the model in the municipalities of the state of Michigan in the United States confirmed that the developed evaluation method describes the extent and rate of deterioration of the fiscal crisis better than the fiscal stress measurement system thus far used in the state government (Kloha et al, 2005, p. 321).

Cohen et al conducted a simulation analysis with six financial ratios of Greek municipalities in order to give each municipality a financial rating and to evaluate the impact of the global financial crisis on the financial health of municipalities (Cohen et al, 2012, pp. 272-273). The most important conclusion made in the study was that the municipalities' revenue base being extensively dependent on external factors, i.e. the fiscal policy of the central government, increases the risk of running into financial difficulties due to the instability of these factors. Analysing the change in the financial ratios of municipalities during the years 2007-2009 confirmed that expenses grew at a higher rate than revenues, further increasing the dependence on support from the central government. (Cohen et al, 2012, pp. 275-276, 278)

Hendrick and Crosby assessed the solvency of the municipalities in the state of Illinois in the Unites States, finding that there were very few municipalities that had poor long-term solvency while having high short-term solvency, which indicates that even good financial management and sound financial decisions will not help to overcome poor long-term solvency. On the other hand, a higher concentration of municipalities having high long-term 
solvency but poor short-term solvency indicated that it is easier for richer municipalities to weaken their solvency by poor financial management and bad financial decisions. (Hendrick, Crosby, 2013, pp. 20-22)

Zafra-Gomez et al analysed the financial data of Spanish municipalities to distinguish municipalities with excellent financial performance from municipalities with poor financial performance. One of the conclusions of the study was that the municipalities with poorer socioeconomic indicators also had poorer financial performance and that municipalities where the share of industrial and tourism enterprises in the regional economy was greater and the average income was higher also showed better financial performance. (Zafra-Gomez et al, 2009, p. 160)

Trussel and Patrick studied the financial data of municipalities in the state of Pennsylvania in the United States to determine which financial indicators help explain falling under fiscal stress. Additionally, the authors prepared a model to predict the risk of encountering fiscal stress. The most important conclusion of the study was that the higher share of administrative expenditures in total expenditures and the lower share of grants received in total revenues reduced the likelihood of encountering fiscal stress. (Trussel and Patrick, 2009, pp. 609-611)

Jones and Walker analysed seven financial and non-financial indicators in municipalities of the state of New South Wales in Australia and reached to conclusion that the financial ratios share of tax revenues in total revenues and total revenues to total assets had the greatest statistical impact in describing how municipalities fell under financial stress. The authors compared the results of the analysis with the watch list made by the state government, indicating municipalities at risk of financial stress, discovering significant differences between the two. (Jones, Walker, 2007, pp. 406, 410-411)

While the overview provided above included only studies published in the $21^{\text {st }}$ century, the methods for evaluating the financial health of municipalities have been developed globally over decades (see Honadle, Jones, 1998, 82). Thorough studies of the field and the existence of indicators and evaluation methods which explain financial difficulties enable us to evaluate the sustainability of municipalities. This also helps to increase the transparency in the use of public funds and to draw attention to upcoming financial difficulties.

An indicator that enables to distinguish municipalities experiencing financial difficulties from municipalities that are not experiencing financial difficulties plays an important role in studies concerning financial difficulties of municipalities. As in many countries (incl. Estonia) municipalities cannot declare bankruptcy when they encounter financial difficulties, then the traditional split "bankrupt" and "non-bankrupt" cannot be used for this purpose. Consequently, the authors of previous studies have proposed using financial ratios, e.g. the need for investment expenditures compared to total revenues (Jones and Walker, 2007, p. 405), as well as the budget deficit indicator describing the difference between the revenues and expenditures in the budget (Trussel and Patrick, 2009, p. 580).

\section{Study methods}

In order to develop a model to predict the risk of running into financial difficulties, the authors used discriminant analysis and logit analysis, which required the municipalities to be previously allocated into groups. The municipalities were divided into two groups using the value of the financial ratio primary operating outcome ${ }^{1}$ to depreciation of tangible fixed assets during the years 2011-2014.

The primary operating outcome is an important financial indicator that describes both the difference between the revenues and expenditures of the primary activities of the municipality 
as well as its own financing capacity, i.e. the ability to make investments and to cover debt financing expenses. A low ratio of primary operating outcome to depreciation of tangible fixed assets increases the risk that the municipality will fail to make investments to replace fixed assets from their own funds upon the lack of external financing sources. Such municipalities depend directly on the investment grants policy of the central government, whereas the change thereof may cause financial difficulties as there are no means to maintain the condition of fixed assets and to make new investments. Jones and Walker have also highlighted the importance of this indicator in evaluating the financial position of municipalities (Jones and Walker, 2007), stating that investment capacity is vital for municipalities to be able to ensure the provision of public services now and in the future.

All municipalities where the value of this ratio was less than or equal to $50 \%$ of the arithmetic mean of the total population were assigned to the risk group and all the rest to non-risk group. The arithmetic mean of the total population divided into groups was 0.91, meaning that the municipalities in the risk group only have own funds to cover $45.5 \%$ of their annual investment needs to maintain the condition of their existing tangible fixed assets. In the opinion of the authors of the study, this method of dividing the municipalities to groups enables to distinguish the municipalities with the lowest ratios from other municipalities, thereby helping the authors conduct the subsequent analysis to reach the meaningful conclusions postulated for the study.

The municipalities whose ratio fell into the lowest or highest $1 \%$ of values (extremes) were excluded from the analysis. Based on the method described above, 41 municipalities were assigned to the risk group and 167 municipalities to the non-risk group. The authors divided both groups into two subgroups based on random selection, using the data of the first part (60\%) to develop the model (source group) and the data of the second part (40\%) to verify the model (control group).

The predictive model was prepared using financial and non-financial data about the total population of the study available from the databases of the Ministry of Finance and the Population Register for the years 2004-2014. The financial data used consists of municipalities' annual accounts prepared on an accrual basis and presented by the municipalities to the Ministry of Finance on a monthly basis.

38 variables were chosen for preparing the model to predict the risk of financial difficulties, dividing these variables into six categories:

1) short-term solvency (two variables),

2) capital structure (four variables),

3) independence (eight variables),

4) flexibility (eight variables),

5) sustainability (eleven variables),

6) size (five variables).

The variables were chosen based on their use in previous studies and their ability to reflect the idiosyncrasies of municipalities' financial management. The short-term solvency variables describe the municipalities' ability to cover short-term liabilities on time. The capital structure variables describe the municipalities' long-term solvency as well as the share of external capital in total capital. The independence, flexibility and sustainability variables describe dependence on external financing, the ability to react to unexpected financial situations and the ability to provide public services now as well as in the future, respectively. The size variables describe the amount of resources at the disposal of the municipalities. 
All variables were subject to an ANOVA analysis, the results of which showed that, of the 38 initial variables, the 9 presented below were statistically significantly different between the two groups (F-test significance level $<5 \%$ ). More than half of these 9 variables (see variables $\mathrm{K}_{4}, \mathrm{~K}_{5}, \mathrm{~K}_{6}, \mathrm{~K}_{7}$ and $\mathrm{K}_{8}$ ) describe the municipalities' financial sustainability, which is a key factor for ensuring a strong local governance system that can organise the provision of highquality public services now as well as in the future. Furthermore, it is necessary for ensuring state's budgetary and macroeconomic stability. Thus, it is essential to use as much as possible sustainability variables for preparing the financial difficulties prediction model. The rest of the variables (see variables $\mathrm{K}_{1}, \mathrm{~K}_{2}, \mathrm{~K}_{3}$ and $\mathrm{K}_{9}$ ) describe municipalities' capital structure, independence, flexibility and size, respectively. All of these above mentioned variables reflect the municipalities' ability to ensure the smooth running of the financial activities. Moreover, these variables are important in ensuring that the municipalities' everyday financial system and the governance run efficiently. Therefore, it is vital to use these variables for developing a model to predict the risk of financial difficulties.

The variable net debt to primary operating outcome $\left(\mathbf{K}_{\mathbf{1}}\right)$ describes over how many years the municipality is capable of covering its debt liabilities if the net debt and the primary operating outcome remain constant. For the risk group, this indicator is high, referring to a lower capacity of raising additional external capital in these municipalities compared to nonrisk group.

The variable investments from own funds to total investments $\left(\mathbf{K}_{2}\right)$ describes dependence on external financing sources in making investments. For the risk group, this indicator is low, referring to the fact that in these municipalities infrastructure development is more dependent on external financing sources compared to the non-risk group and the ability to maintain the level of investments is at risk if external financing sources are no longer available.

The variable share of primary operating outcome in primary operating revenues $\left(\mathbf{K}_{3}\right)$ describes own financing capacity and reflects the ability to react to unexpected financial difficulties. For the risk group, this figure is lower than for the non-risk group, indicating that these municipalities are in a poorer position in terms of making investments from their own funds and being capable of handling unexpected financial situations independently.

The variable population change $\left(\mathbf{K}_{\mathbf{4}}\right)$ describes the change in the demographic situation. For the risk group, this figure is low, indicating that the attractiveness of the living environment in these municipalities is fading compared to the non-risk group.

The variable share of municipality employees among the tax-payers of the municipality $\left.\mathbf{K}_{\mathbf{5}}\right)$ describes how many of the tax-payers of the municipality are tax-payers working for the municipality. For the risk group, this figure is high, indicating that the business environment in these municipalities is less attractive than that in the non-risk group.

The variables municipality employees' salary to the residents' average income $\left(\mathbf{K}_{6}\right)$ and municipality employees' (except managers) salary to the residents' average income $\left(K_{7}\right)$ describe the ratio between the income of municipality employees and the average income of residents of the municipality. This figure is low for the risk group, indicating that these municipalities are under greater pressure to raise payroll expenses in the budget and their competitiveness in attracting highly qualified specialists from the labour market is lower than that of the non-risk group.

The variable accumulated depreciation of tangible fixed assets to acquisition cost (K8) describes the condition of tangible fixed assets. This figure is high for municipalities in the risk group, indicating that the tangible fixed assets in these municipalities are older compared 
to the municipalities in the non-risk group. This situation exerts expense pressure on the municipality's budget in the form of higher maintenance costs and greater investment needs.

The variable primary operating outcome $(\mathbf{K} \mathbf{9})$ describes the amount of the primary operating outcome at the municipality's disposal. For the risk group, this figure is low, indicating that smaller municipalities are at a greater risk of encountering financial difficulties.

The subsequent analysis will use the variables which were determined to be statistically significant between the two groups, to develop a model to predict the risk of a municipality encountering financial difficulties which would have the greatest possible classification accuracy.

\section{Results of discriminant analysis}

Several statistical preconditions must be met in order to conduct a discriminant analysis. The first step was to assess the covariance matrices of the two groups using Box's M-test. The test results confirmed that the covariance matrices of the two groups were similar when all variables were used, enabling the authors to continue with the linear discriminant analysis.

The next step was to assess the correlation between the variables, as multicollinearity may cause parameter values which are difficult to interpret, meaning that it is recommended to not have several of them in the same model. The Pearson correlation coefficients between variables have been presented in table 1, where the correlations stronger than 0.5 have been indicated in bold. In the subsequent analysis, the pairs of variables $K_{2}$ and $K_{9}, K_{3}$ and $K_{9}, K_{6}$ and $\mathrm{K}_{7}$ were not included in the model at the same time.

Table 1. Correlation matrix of variables used in discriminant analysis

\begin{tabular}{|c|c|c|c|c|c|c|c|c|c|}
\hline & $\mathrm{K}_{1}$ & $\mathrm{~K}_{2}$ & $\mathrm{~K}_{3}$ & $\mathrm{~K}_{4}$ & $\mathrm{~K}_{5}$ & $\mathrm{~K}_{6}$ & $\mathrm{~K}_{7}$ & $\mathrm{~K}_{8}$ & $\mathrm{~K}_{9}$ \\
\hline $\mathrm{K}_{1}$ & 1.00 & & & & & & & & \\
\hline $\mathrm{K}_{2}$ & 0.05 & 1.00 & & & & & & & \\
\hline $\mathrm{K}_{3}$ & -0.28 & 0.49 & 1.00 & & & & & & \\
\hline $\mathrm{K}_{4}$ & -0.13 & 0.37 & 0.36 & 1.00 & & & & & \\
\hline $\mathrm{K}_{5}$ & 0.07 & -0.34 & -0.17 & -0.34 & 1.00 & & & & \\
\hline $\mathrm{K}_{6}$ & -0.09 & 0.17 & 0.16 & -0.09 & 0.05 & 1.00 & & & \\
\hline $\mathrm{K}_{7}$ & -0.08 & 0.12 & 0.12 & -0.11 & 0.14 & 0.96 & 1.00 & & \\
\hline $\mathrm{K}_{8}$ & -0.06 & 0.03 & 0.02 & -0.01 & 0.16 & 0.05 & 0.06 & 1.00 & \\
\hline $\mathrm{K}_{9}$ & -0.07 & 0.66 & 0.55 & 0.32 & -0.31 & 0.10 & 0.12 & -0.07 & 1.00 \\
\hline
\end{tabular}

Source: The authors' calculations based on data from the Ministry of Finance.

The third step was to assess the a priori likelihoods of belonging to a certain group as the sizes of the risk group and the non-risk group are different. Based on the analysis, the a priori likelihoods were $20 \%$ and $80 \%$ respectively.

The testing of alternative models was conducted using the statistics software SPSS, where it is possible, in addition to adding all the variables at once, to add the variables step by step (the stepwise method), adding variables until the statistical significance of the model can no longer be improved. Upon testing the models, it was determined that the best one was the model with seven independent variables (classification accuracy $88 \%$ for the source group and $82 \%$ for the control group) with the following discriminant equation:

$$
\begin{aligned}
D=3.275+ & 0.086 K_{1}-1.328 K_{2}-10.860 K_{3}+2.333 K_{4}+0.328 K_{5}-5.284 K_{7} \\
+ & 8.329 K_{8}
\end{aligned}
$$


The discriminant score range, i.e. the grey area, which contained $90 \%$ of the incorrect classifications is $-0.57 \ldots 1.83$, whereas the midpoint of this range, i.e. 1.2, is the model's cut off point where municipalities with a higher score were allocated to the risk group and vice versa.

Table 2. The impact of variables on the model's classification effectiveness

\begin{tabular}{|l|r|}
\hline Variable & Function \\
\hline $\mathrm{K}_{3}$ & -0.54 \\
\hline $\mathrm{K}_{8}$ & 0.50 \\
\hline $\mathrm{K}_{7}$ & -0.37 \\
\hline $\mathrm{K}_{2}$ & -0.34 \\
\hline $\mathrm{K}_{1}$ & 0.30 \\
\hline $\mathrm{K}_{5}$ & 0.14 \\
\hline $\mathrm{K}_{4}$ & -0.11 \\
\hline
\end{tabular}

Source: The authors' calculations based on data from the Ministry of Finance.

In evaluating the variables (see Table 2) it was discovered that the most important variables in distinguishing the two groups are share of primary operating outcome in primary operating revenues $\left(\mathrm{K}_{3}\right)$ and accumulated depreciation of tangible fixed assets to acquisition cost $\left(\mathrm{K}_{8}\right)$. The least significant variable is population change $\left(\mathrm{K}_{4}\right)$ and a similarly small descriptive capacity is held by the share of municipality employees among the tax-payers of the municipality $\left(\mathrm{K}_{5}\right)$.

\section{Results of logit analysis}

Conducting a logit analysis is significantly simpler compared to discriminant analysis as there is no need to ensure that as many statistical preconditions have been satisfied. Nevertheless, the multicollinearity of independent variables is a significant risk and, consequently, similar to the discriminant analysis, the authors followed the principle that variables that have a stronger correlation than 0.5 will not be added to the same model (see Table 1).

Alternative models were tested using three methods: adding all variables at once and two stepwise methods where the first involved adding variables until the model's statistical significance could no longer be improved (forward) and the second involved first adding all the variables and then removing these until the model's statistical significance could no longer be improved (backward). Upon testing, the best model turned out to be a model with seven variables, achieving a classification accuracy of $87 \%$ for the source group and $84 \%$ for the control group using 0.5 as the cut-off point. The authors also tested cut-off points in the range $0.3 \ldots 0.7$ but this did not enable to improve the model's classification accuracy.

Similarly, to the discriminant analysis, the logit analysis let us calculate a score for each municipality (logit score) which can be used to express the likelihood of falling into the risk group based on the following formula:

$$
p=\frac{1}{1+e^{L}},
$$

where

$p$ - likelihood of falling into the risk group;

$L-$ logit score. (Trussel and Patrick, 2009, p. 600) 
The logit score equation of the model with the highest classification accuracy determined as a result of the analysis is the following:

$$
\begin{aligned}
\boldsymbol{L}=-11.541 & -0.124 K_{1}+5.044 K_{2}+55.889 K_{3}-0.637 K_{4}+9.395 K_{5}+12.477 K_{7} \\
& -11.909 K_{8}
\end{aligned}
$$

The model's descriptive capacity, i.e. goodness of fit, is 61\% (Hosmer- Lemeshow test) and the arithmetic mean likelihood of falling into the risk group is $20 \%$ for the source group and $19 \%$ for the control group.

Table 3. The impact of the variables on the model's differentiating capacity

\begin{tabular}{|l|r|}
\hline Variable & \multicolumn{1}{|l|}{$\begin{array}{l}\text { Wald } \\
\text { statistics }\end{array}$} \\
\hline $\mathrm{K}_{3}$ & 11.242 \\
\hline $\mathrm{K}_{8}$ & 8.234 \\
\hline $\mathrm{K}_{7}$ & 5.951 \\
\hline $\mathrm{K}_{2}$ & 3.129 \\
\hline $\mathrm{K}_{1}$ & 2.220 \\
\hline $\mathrm{K}_{5}$ & 0.962 \\
\hline $\mathrm{K}_{4}$ & 0.004 \\
\hline
\end{tabular}

Source: The authors' calculations based on data from the Ministry of Finance.

Upon evaluating the variables (see table 3) it was determined that the highest descriptive capacity based on the Wald statistic is held by share of primary operating outcome in primary operating revenues $\left(\mathrm{K}_{3}\right)$, followed by accumulated depreciation of tangible fixed assets to acquisition cost $\left(\mathrm{K}_{8}\right)$. Similarly, to the discriminant analysis, the variables with the lowest descriptive power are share of municipality employees in the municipality among the taxpayers of the municipality $\left(\mathrm{K}_{5}\right)$ and population change $\left(\mathrm{K}_{4}\right)$.

\section{Conclusions}

Both in the discriminant analysis and the logit analysis, the variable with the highest descriptive capacity was the share of primary operating outcome in primary operating revenues, indicating a strong link between own financing capacity and the risk of encountering financial difficulties. This was predictable as the respective variable reflects the ability to make investments from own funds and to pay debt financing expenses, which are both vital in terms of municipalities' sustainability. The same conclusion has been reached by authors of previous studies (Cohen et al, 2012, Zafra-Gomez et al, 2009, Trussel and Patrick, 2009, Jones and Walker, 2007), indicating that greater independence (i.e. independence from central government support) ensures budget flexibility and the ability to react to unexpected financial difficulties quickly, enabling the municipality to avert the crisis.

The variable accumulated depreciation of tangible fixed assets to acquisition cost was ranked second in terms of descriptive capacity in both models, indicating that municipalities that have a higher risk of encountering financial difficulties characteristically have older fixed assets compared to other municipalities. In combination with the low values of the variables investments from own funds to total investments and share of primary operating outcome in primary operating revenues and a high value of net debt to primary operating outcome, the ability of these municipalities to maintain the sustainability of their fixed assets is directly dependent on the existence of external support. The authors consider this as something to worry about as these are municipalities which are characterised by the law ratio of municipality employees' (except managers) salary to the residents' average income which in 
turn adds expenditure pressure on the budget and reduces the ability to attract highly qualified specialists. The lack of such specialists has been highlighted by previous authors (Helden, $2000,87)$ as one of the major reasons for explaining why municipalities run into financial difficulties.

In both models, the variables with the lowest descriptive capacity were share of municipality employees among the tax-payers of the municipality $\left(\mathrm{K}_{5}\right)$ and population change $\left(\mathrm{K}_{4}\right)$. In the authors' opinion, for the first variable, this is most probably due to the fact that it reflects financial difficulties in the future and, for the second one, the general trend of population decrease, which is characteristic to most Estonian municipalities.

\section{Notes}

${ }^{1}$ Difference between primary operating revenues (tax revenues, sales of goods and services, grants received (except grants received for acquisition of fixed assets), other operating revenues) and primary operating expenditures (grants given (except grants given for acquisition of fixed assets), other operating expenses).

\section{Literature}

Altman, E. I. (2000). Predicting Financial Distress of Companies: Revisiting the Z-Score and Zeta ${ }^{\circledR}$ Models. New York University, Stern School of Business.

Becchetti, L., Sierra, J. (2003). Bankruptcy risk and productive efficiency in manufacturing firms. Journal of Banking \& Finance, no. 27, pp. 2099-2120.

Cohen, S., Doumpos, M., Neofytou, E., Zopounidis, C. (2012). Assessing financial distress where bankruptcy is not an option: An alternative approach for local municipalities. European Journal of Operational Research, no. 218, pp. 270-279.

Hendrick, R., Crosby, A. (2013). Bankruptcy Triggers and their Relation to Fiscal Solvency: An Examination of Local Governments in Illinois. In: Paper prepared for presentation at the annual conference of the Association for Budgeting and Financial Management, Washington, DC, October 3-4, 2013, University of Illinois at Chicago.

Helden, G. J. (2000). Is financial stress an incentive for the adoption of businesslike planning and control in local government? A comparative study of eight dutch municipalities. Financial Accountability \& Management, no. 16, pp. 83-100.

Honadle, B. W., Jones, M. L. (1998). Analyzing Rural Local Governments' Financial Condition: An Exploratory Application of Three Tools. Public Budgeting \& Finance, no. 18, pp. 69-86.

Jones, S., Walker, R. G. (2007). Explanators of Local Government Distress. Abacus, No. 43, pp. 396-418.

Kloha, P., Weissert, C. S., Kleine, R. (2005). Developing and Testing a Composite Model to Predict Local Fiscal Distress. Public Administration Review, no. 65, pp. 313-323.

Municiapalities` financial and non-financial data during the years 2004-2014. Ministry of Finance Database.

Municiapalities population information during the years 2004-2014. Population Register Database.

Ohlson, J. A. (1980). Financial Ratios and the Probabilistic Prediction of Bankruptcy. Journal of Accounting Research, no. 18, pp. 109-131. 
Pompe, P. P. M., Bilderbeek, J. (2005). The prediction of bankruptcy of small- and mediumsized industriaal firms. Journal of Business Venturing, no. 20, pp. 847-868.

Trussel, J. M., Patrick, P. A. (2009). A predictive model of fiscal distress in local governments. Journal of public budqeting accounting and financial management, no. 21, pp. $578-616$.

Zafra-Gómez, J. L., López-Hernịndez, A. M., Hernịndez-Bastida, A. (2009). Evaluating financial performance in local government: maximizing the benchmarking value. International Review of Administrative Sciences, no. 75, pp. 151-167. 